\title{
Excitation of Tuberoinfundibular Dopamine Neurons by Oxytocin: Crosstalk in the Control of Lactation
}

\author{
DVirginie Briffaud, Paul Williams, Justine Courty, and Christian Broberger \\ Department of Neuroscience, Karolinska Institutet, Retzius väg 8, 17177 Stockholm, Sweden
}

\begin{abstract}
Milk production in the nursing mother is induced by the hormone prolactin. Its release from the anterior pituitary is generally under tonic inhibition by neuroendocrine tuberoinfundibular dopamine (TIDA) neurons of the arcuate nucleus. Successful nursing, however, requires not only production but also ejection of breast milk. This function is supported by the hormone oxytocin. Here we explored the possibility that interaction between these functionally complementary hormones is mediated by TIDA neurons. First, whole-cell patchclamp recordings were performed on prepubertal male rat hypothalamic slices, where TIDA neurons can be identified by a robust and rhythmic membrane potential oscillation. Oxytocin induced a switch of this rhythmic activity to tonic discharge through a depolarization involving direct actions on TIDA neurons. The depolarization is sensitive to blockade of the oxytocin receptor and is mediated by a voltage-dependent inward current. This inward current has two components: a canonical transient receptor potential-like conductance in the low-voltage range, and in the high-voltage range, $\mathrm{a} \mathrm{Ca}^{2+}$-dependent component. Finally, whole-cell and loose-patch recordings were also performed on slices from virgin and lactating female rats to evaluate the relevance of these findings for nursing. In these preparations, oxytocin was found to excite TIDA neurons, identified by their expression of tyrosine hydroxylase. These findings suggest that oxytocin can modulate prolactin secretion by exciting TIDA neurons, and that this may serve as a feedforward inhibition of prolactin release.
\end{abstract}

Key words: arcuate nucleus; oscillation; prolactin

\section{Introduction}

Reproductive behavior is essential for species persistence by ensuring birth and survival of offspring. The hypothalamus and its interactions with the pituitary play a key role in reproduction by orchestrating the release of hormones vital for each phase from courtship to parental behavior (Bronson, 1991). Among these hormones, prolactin (PRL), which rises dramatically in blood during late pregnancy and nursing, supports a number of functions, e.g., decreased fertility, accumulation of energy stores and maternal behavior, but is best known for its powerful stimulatory action on mammary gland milk production (Freeman et al., 2000). Under most conditions, PRL release is tonically inhibited by neurosecretory tuberoinfundibular dopamine (TIDA; Fuxe, 1963; Björklund et al., 1971) neurons in the hypothalamic dorsomedial arcuate nucleus (dmArc; Lyons and Broberger, 2014).

Received June 27, 2014; revised Jan. 27, 2015; accepted Jan. 31, 2015

Author contributions:V.B. and C.B. designed research;V.B.,P.W., and J.C. performed research;V.B., P.W., and J.C. analyzed data; V.B. and C.B. wrote the paper.

This work was supported by a Starting Investigator Grant from the European Research Council (ENDOSWITCH 261286), the Swedish Research Council (2010-3250), the Strategic Research Programme in Diabetes at Karolinska Institutet, and the Boehringer Ingelheim Foundation. We thank DrD. J. Lyons, Dr A. El Manira, A. S. Stagkourakis, and A. Hellysaz for expert advice and the other members of the Broberger laboratory for helpful discussions.

The authors declare no competing financial interests.

Correspondence should be addressed to either Dr Virginie Briffaud or Christian Broberger, Department of Neuroscience, Karolinska institutet, Retzius väg 8, 17177 Stockholm, Sweden. E-mail: virginie.briffaud@ki.se or Christian.Broberger@ki.se.

DOI:10.1523/JNEUROSCI.2633-14.2015

Copyright $\odot 2015$ the authors $\quad 0270-6474 / 15 / 354229-09 \$ 15.00 / 0$
Yet, efficient lactation requires not only milk production but also milk ejection. The latter is primarily induced by oxytocin (OT), a nonapeptide released by magnocellular neurons of the paraventricular and supraoptic nuclei (Ott and Scott, 1910; Du Vigneaud et al., 1953). Similar to PRL, OT release increases in response to stimuli such as suckling, mating, and estrogen (Bertram et al., 2010). Given the functional interrelationship of PRL and OT in reproductive behavior, it seems likely that some form of crosstalk between the two signaling pathways could allow for coordination. Indeed, PRL can stimulate OT release from magnocellular neurons (Parker et al., 1991). Conversely, systemically administered OT can stimulate PRL secretion through actions on lactotroph cells (Lumpkin et al., 1983; Samson et al., 1986; Arey and Freeman, 1989). Paradoxically, however, central administration of OT causes a reduction in plasma PRL (Lumpkin et al., 1983). An earlier study has suggested that OT excites unidentified neurons in the dmArc and increases dopaminergic output toward the pituitary (Yuan and Pan, 1996). Here, we addressed whether direct actions of OT on TIDA cells in rats may explain inhibition of PRL release and explored the underlying cellular mechanisms.

\section{Materials and Methods}

Animals for electrophysiology experiments. The experiments were performed on three groups of Sprague-Dawley rats (Charles River Laboratories): virgin (8- to 12-week-old) females, lactating females housed with $8-12$ pups (7-9 or 22 -d-old), or prepubertal (21- to 30 -d-old) males. The animals had ad libitum access to food and water in a light- and temperature-controlled environment. The experiments were conducted in accordance with the European Community Council directive of No- 
vember 24, 1986 (86/609/EEC) and had received prior approval by the local ethical board (Stockholms Norra Djurförsöksetiska Nämnd).

Slice preparation and data recordings. Virgin female and lactating rats were deeply anesthetized and transcardially perfused with ice-cold oxygenated slicing artificial CSF ( $\mathrm{aCSF}$ ) containing the following (in $\mathrm{mm}$ ): 213 sucrose, $2.5 \mathrm{KCl}, 1.3 \mathrm{NaH}_{2} \mathrm{PO}_{4}, 26 \mathrm{NaHCO}_{3}, 2 \mathrm{MgSO}_{4}, 2 \mathrm{CaCl}_{2}$, and 10 D-glucose. Prepubertal male rats were decapitated without prior perfusion. The dissected brain was quickly placed in slicing aCSF. Coronal hypothalamic slices ( $250 \mu \mathrm{m}$ thick) containing the dmArc were cut on a vibratome as previously described (Lyons et al., 2010). Voltage- and current-clamp whole-cell and loose-patch recordings were performed at room temperature and slices were continuously perfused with oxygenated "control" aCSF containing the following (in mM): $127 \mathrm{NaCl}, 2 \mathrm{KCl}$, $1.2 \mathrm{NaH}_{2} \mathrm{PO}_{4}, 26 \mathrm{NaHCO}_{3}, 1.3 \mathrm{MgSO}_{4}, 2.4 \mathrm{CaCl}_{2}$, and 10 D-glucose. For whole-cell recordings, patch pipettes were filled with a solution containing the following (in mM): $140 \mathrm{~K}$-gluconate, $10 \mathrm{KCl}, 1 \mathrm{KOH}, 1 \mathrm{EGTA}, 2$ $\mathrm{Na}_{2}$ ATP, 10 HEPES, pH 7.3, 280-290 mOsm. For loose-patch recordings, micropipettes were filled with control aCSF. For recordings using slices from virgin female and lactating rats, neurobiotin $(0.2 \%$; Vector Laboratories) was also included in the intrapipette solution. Recordings were made with a Multiclamp 700B amplifier (Molecular Devices). The signal was amplified and low-pass filtered on-line at $10 \mathrm{kHz}$, digitized (Digidata 1322A or Digidata 1440A, Molecular Devices), and stored on a personal computer using Clampex v9.2 or 10.3 software (Molecular Devices). Slow and fast capacitive components were automatically compensated for. Liquid junction potential was not compensated. For experiments performed with prepubertal male rats, access resistance was monitored throughout the experiment. Only cells with an access resistance $<25 \mathrm{M} \Omega$ and that changed $<15 \%$ during the course of recording were included in analysis. For the voltage-clamp experiments, TIDA neurons were identified by the presence of an oscillatory activity observed first in current-clamp and which persisted after switch to voltage-clamp configuration.

Pharmacological agents. All pharmacological compounds were bath applied. Tetrodotoxin (TTX) was purchased from Alomone Labs. Oxytocin nonapeptide, the OT-receptor (OT-R) agonist, $\left(\mathrm{Thr}^{4}, \mathrm{Gly}^{7}\right)$ oxytocin (TGOT), and the OT-R antagonist, $\left(\mathrm{d}\left(\mathrm{CH}_{2}\right)_{5}^{1}\right.$, Tyr $(\mathrm{Me})^{2}, \mathrm{Thr}^{4}$, Orn ${ }^{8}$, des-Gly $\mathrm{NH}_{2}^{9}$ )-vasotocin (OTA), were purchased from Bachem. 6-Cyano-7-nitroquinoxaline-2,3-dione (CNQX), 2-amino-5-phosphonopentanoic acid (AP-5), 2-aminoethoxydiphenylborate (2-APB), flufenamic acid, and paxilline were purchased from Tocris Bioscience. Picrotoxin was purchased from Sigma-Aldrich. To investigate the involvement of specific ionic species, modified aCSF was used for some recordings. The $\mathrm{Na}^{+}$-substituted aCSF had an equimolar concentration of Tris-hydrochloride (Tris- $\mathrm{HCl} ; 127 \mathrm{~mm}$ ) instead of $\mathrm{NaCl}$. The low- $\mathrm{Ca}^{2+}$ aCSF had the following composition (in $\mathrm{mm}$ ): $127 \mathrm{NaCl}, 1.9 \mathrm{KCl}, 1.2 \mathrm{NaH}_{2} \mathrm{PO}_{4}, 26 \mathrm{NaHCO}_{3}, 4.5 \mathrm{MgSO}_{4}, 0.15$ $\mathrm{CaCl}_{2}$, and $10 \mathrm{D}$-glucose.

Immunofluorescence. For the immunofluorescence study of the tyrosine hydroxylase (TH)-OT anatomical relationship, 4- to 6-week-old male $(n=3)$ and virgin female $(n=4)$ rats, as well as lactating female $(n=7)$ rats nursing litters of 8 -d-old pups $7 \mathrm{~d}$ after birth were anesthetized and transcardially perfused with a $4 \%$ formalin $/ 0.4 \%$ picric acid fixative. Following cryoprotection in $15 \%$ sucrose, brains were frozen and cut into $14-\mu \mathrm{m}$-thick coronal sections. The sections were collected on glass slides (VWR). Then, the sections were incubated with polyclonal guinea pig anti-OT primary antiserum (1:4000; Millipore; AB15704) and monoclonal mouse anti-TH primary antibodies (1:2000; Millipore; MAB318) at $4^{\circ} \mathrm{C}$ overnight followed by incubation for $120 \mathrm{~min}$ at room temperature with green-fluorescent AlexaFluor 488 dye-labeled goat anti-guinea pig secondary antibodies (1:500; Invitrogen, A11073) and red-fluorescent AlexaFluor 594 dye-labeled donkey anti-mouse secondary antibodies (1:500; Invitrogen; A21202) and mounted with glycerol supplemented with an anti-fade agent (2.5\% 1,4-diazabicyclo [2.2.2] octane, Sigma-Aldrich). Recorded cells in slices from virgin female and lactating rats were reconstructed and stained for TH following immersion in fixative as above by $48 \mathrm{~h}$ incubation with fluorescein isothiocyanate-conjugated avidin (1:2500; Invitrogen) and monoclonal anti-TH antibodies (1:2000; Millipore) at $4^{\circ} \mathrm{C}$. Slices were then incubated for $24 \mathrm{~h}$ in AlexaFluor 594 dye-labeled donkey anti-rabbit secondary antisera (1:500; Invitrogen) and mounted on glass slides as above. The immunofluorescence protocols have previously been described (Lyons et al., 2010, 2012). Tissues were imaged using a Zeiss Axioimager M1 microscope and Neurolucida software. Confocal image stacks were sampled and processed with an Olympus FV1000 Confocal Laser Scanning Microscope at the Center for Live Cell Imaging of Cells at Karolinska Institutet.

Data analysis. Data processing was performed using OpenElectrophy open-access software (Garcia and Fourcaud-Trocme, 2009).

For recordings performed on slices from prepubertal male rats, the duration of tonic episode corresponded to the longest nadir-to-nadir interval following OT application. Mean membrane potential values as well as mean current values recorded during TTX application corresponded to the average of $10 \mathrm{~s}$ signals sampled before drug application and at the maximum of the effect when evident. When not evident, signal was sampled with a delay similar to the delay observed to obtain TTX effect. For current- and voltage-clamp recordings, neurons were considered as responding if they exhibited a variation of the membrane potential or current $>3 \mathrm{mV}$ or $3 \mathrm{pA}$, respectively.

For the experiments performed on slices from virgin female and lactating rats, the firing pattern of each cell was determined for control and drug period using visual observation, bimodality coefficient (BC) and the coefficient of variation $(\mathrm{CV})$. The $\mathrm{BC}$ corresponded to the following:

$$
B C=\frac{m_{3}^{2}+1}{m_{4}+3 \frac{(n-1)^{2}}{(n-2)(n-3)}}
$$

with $m_{3}$ the skewness of the interspike interval distribution and $m_{4}$ its excess kurtosis.

The CV was defined as the ratio of the SD of the interspike interval to the mean. Four firing patterns were distinguished: null when few or no action potentials (APs), tonic when $\mathrm{BC}<0.9$ and $\mathrm{CV}<1$, mixed when $\mathrm{BC}<0.9$ and $\mathrm{CV}>1$, and bursting when $\mathrm{BC}>0.9$ and $\mathrm{CV}>1$. A cell was considered as responding to OT if the firing pattern changed between the groups defined above or if the mean number of APs per $10 \mathrm{~s}$ measured during $2 \mathrm{~min}$ in the presence of OT was higher or lower than the mean number of APs per $10 \mathrm{~s}$ measured during 2 min of the control period \pm 2 SDs. For cells that did not reach the threshold for AP discharge, the same analysis criteria were applied to mean membrane potential.

Statistical analysis. Statistical tests were performed with Python scripts or with GraphPad Prism software package. Significance was defined as $p<0.05\left({ }^{*} p<0.05,{ }^{* * *} p<0.01,{ }^{* * *} p<0.001\right)$. The specific statistical test applied is indicated with the corresponding results. Quantified results are presented as mean \pm SEM.

\section{Results}

\section{OT directly excites TIDA neurons}

First, we addressed whether OT can affect the excitability of TIDA neurons in slice preparations from prepubertal male rats. In this preparation, TIDA neurons can be reliably identified by their electrophysiological properties, including a robust, spontaneous stereotyped membrane potential oscillation (Lyons et al., 2010). Upon bath application of OT $(1 \mu \mathrm{M})$, TIDA neurons consistently exhibited an excitatory response in the form of a switch from rhythmic to tonic discharge reversible upon washout $(n=6 / 6$; Fig. $1 A$ ). The tonic episode lasted on average $87.6 \pm 10.7 \mathrm{~s}$ with an average firing frequency of $2.0 \pm 0.4 \mathrm{~Hz}(n=6)$. A second application of OT, performed $\approx 20 \mathrm{~min}$ after the initial exposure, induced a tonic firing episode of a duration not significantly different from that following the first application $(65.0 \pm 16.5 \mathrm{~s}$, $n=4$; Wilcoxon test, $p>0.05$ ), indicating the absence of significant desensitization. Moreover, the duration of OT application appeared not to influence the duration of the tonic episode $(30 \mathrm{~s}$ application: $87.6 \pm 10.7 \mathrm{~s}, n=6 ; 20 \mathrm{~min}$ application: $94.8 \pm$ 13.7 s, $n=3$; Mann-Whitney test, $p>0.05$ ). 
$\mathrm{Aa}$

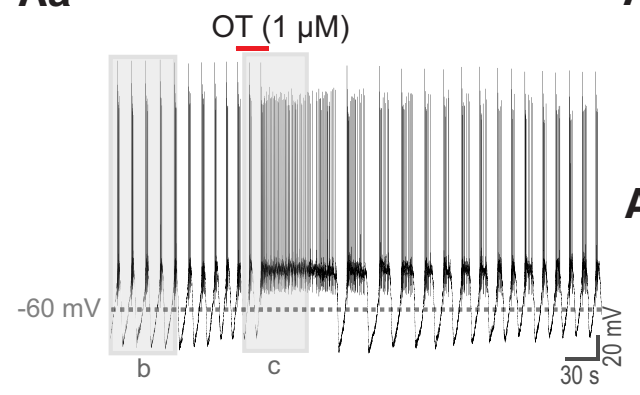

$A b$

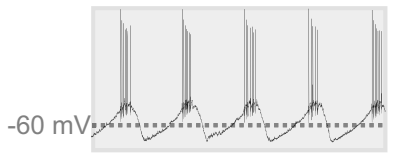

Ac

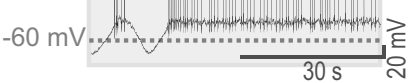

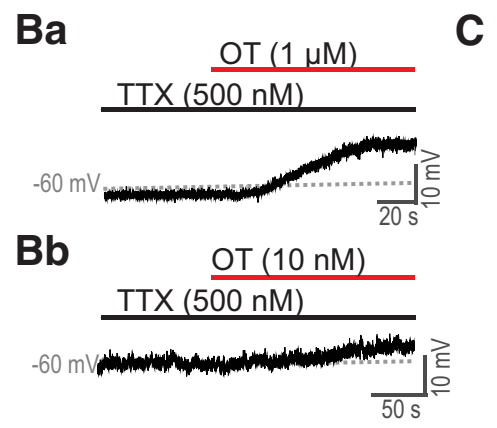

C

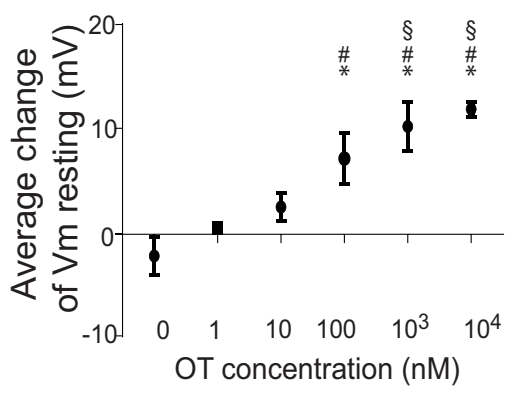

D

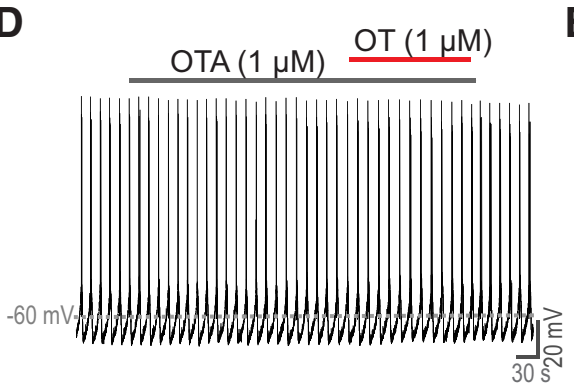

$\mathbf{E}$

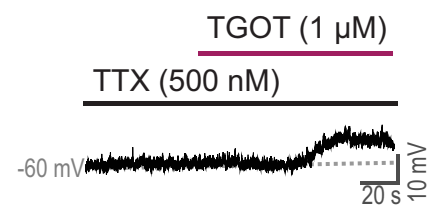

Figure 1. OT directly excites TIDA neurons via the 0 T receptor. $A$, Current-clamp whole-cell recording of a TIDA neuron in slice from prepubertal male rat. Portions of trace indicated by boxes in $\boldsymbol{A} \boldsymbol{a}$ shown expanded in $\boldsymbol{A} \boldsymbol{b}$ and $\boldsymbol{A c}$. Note typical rhythmic membrane potential oscillation under control conditions $(\boldsymbol{A} \boldsymbol{b})$. $0 \mathrm{~T}$ administration is followed by a switch of the activity from rhythmic to tonic ( $\boldsymbol{A c}$ ). $\boldsymbol{B}$, Current-clamp recordings of TIDA neurons in the presence of TTX. Application of OT at $1 \mu \mathrm{M}(\boldsymbol{B a})$ or $10 \mathrm{nM}$ $(\boldsymbol{B} \boldsymbol{B})$ induces a depolarization. $\boldsymbol{C}$, Dose-response histogram illustrating the relationship between $0 \mathrm{~T}$ concentration and the resultant membrane potential depolarization. Cells included have been exposed to a single concentration. At least five cells are included for each concentration. The Wilcoxon test was used to perform the statistical analysis between each condition: ${ }^{*} p<0.01$ compared with $0 \mathrm{~T}$ concentration of $0 \mathrm{~nm}$; \#p $<0.01$ compared with $0 \mathrm{~T}$ concentration of $1 \mathrm{~nm}$ and $\$ p<0.05$ compared with $0 \mathrm{~T}$ concentration of $10 \mathrm{~nm}$. No statistical difference measured between 1 and $10 \mu \mathrm{m}$. Vm: membrane potential. $\boldsymbol{D}$, Representative TIDA neuron current-clamp recording performed with application of OTA. In the presence of the antagonist, $0 \mathrm{~T}$ administration fails to induce a switch of discharge activity. $\boldsymbol{E}$, Current-clamp recording of a TIDA neuron in the presence of TTX. Application of the selective receptor agonist, TGOT, induces a depolarization.

To determine whether OT directly excites TIDA neurons, we examined its effect during blockade of fast ionotropic transmission by bath application of CNQX (10 $\mu \mathrm{M}$; AMPA receptor antagonist), AP-5 (25 $\mu \mathrm{M}$; NMDA receptor antagonist) and picrotoxin $\left(100 \mu \mathrm{M} ; \mathrm{GABA}_{\mathrm{A}}\right.$ receptor antagonist). Under these conditions, the switch from rhythmic to tonic firing in response to administration of OT persisted $(n=5 / 5)$, with duration of the tonic episode $(56.5 \pm 8.1 \mathrm{~s})$ not significantly different from that observed in the absence of synaptic blockers (Mann-Whitney test, $p>0.05$ ).

Application of the blocker of voltage-gated $\mathrm{Na}^{+}$channels, TTX, abolishes the TIDA oscillation (Lyons et al., 2010). In the presence of TTX (500 nM), OT administration induced a membrane potential depolarization (Fig. 1B). With $1 \mu \mathrm{M}$ OT, the average amplitude of the depolarization was $+10.4 \pm 2.4 \mathrm{mV}$
( $n=6$, Wilcoxon test, $p<0.05)$. This effect was not accompanied by a significant change of input resistance (control: $1354.3 \pm 136.4 \mathrm{M} \Omega$; OT: $1298.1 \pm 107.4$ $\mathrm{M} \Omega, n=5$; Wilcoxon test, $p>0.05)$ and exhibited a dose-response relationship $\left(\mathrm{EC}_{50}=37.6 \mathrm{nM}\right.$ when dose-response curve fitted using nonlinear regression model; Fig. 1C). These results show that OT can act directly on TIDA neurons to induce an excitation.

$O T$ acts via the $O T$ receptor and induces a net inward current in TIDA neurons OT binds to the OT-R but also, with lower affinity, to V1a, V1b, and V2 vasopressin receptors (Stoop, 2012). To address which receptor mainly mediated OT-induced excitation of TIDA neurons, the OT-R was blocked by bath application of the specific antagonist, OTA ( $1 \mu \mathrm{M}$; Manning et al., 2008). Under these conditions, OT did not induce a switch of discharge pattern (Fig. 1D). In the presence of TTX and the OT-R antagonist, no membrane potential depolarization could be observed (average change: $-0.3 \pm 0.9 \mathrm{mV}, n=5$ ), whereas a second application of OT, after OTA had been washed out of the bath, resulted in an average depolarization of $+7.8 \pm 1.2 \mathrm{mV}$; the average depolarization was significantly different between the first and the second OT application (Wilcoxon test, $p<0.05$ ). Bath application of TGOT $(1 \mu \mathrm{M})$, a selective OT-R agonist (Manning et al., 2008), induced a depolarization of $6.2 \pm 1.4 \mathrm{mV}(n=$ $5 / 8$; Fig. $1 E$ ). This average depolarization was not significantly different from that observed with OT (Mann-Whitney test, $p>0.05)$. These findings support a specific activation of the OT-R by OT underlying the excitation of TIDA neurons.

Next, we wanted to characterize the changes in TIDA neuron membrane properties caused by OT. In voltage-clamp recordings performed at a holding potential of $-60 \mathrm{mV}$ and in the presence of TTX, OT reversibly induced a net inward current with an average amplitude of $-13.2 \pm 3.6 \mathrm{pA}(n=$ $8 / 8$; Wilcoxon test between control and OT application, $p<0.05$; Fig. 2A).

To examine the changes in membrane current across the membrane potential range, voltage-clamp ramps from -110 to $+30 \mathrm{mV}$ were applied (Fig. $2 B$ ). Subtraction of the ramp performed in control conditions from the ramp performed at the peak of OT response revealed a biphasic, largely inward OT-induced current $\left(I_{\mathrm{OT}}\right)$ displaying two reversals, the first $\sim-20 \mathrm{mV}$ and the second $\sim 0 \mathrm{mV}$ (Fig. $2 C$ ). This currentvoltage relationship suggests that $I_{\mathrm{OT}}$ is composed of two components: one below $-10 \mathrm{mV}$ ("low-voltage component"; LV) and one above $-10 \mathrm{mV}$ ("high-voltage component"; HV). 
Ionic mechanisms underlying $I_{\mathrm{OT}}$

Previous studies of TIDA neurons have identified an LV-like current carried by a mixed cationic conductance as a target for neuromodulation (Lyons et al., 2010, 2012). Recording of TIDA neurons in voltage-clamp mode at a holding potential of $-60 \mathrm{mV}$ and in the presence of TTX (same configuration as shown in Fig. 2Aa) revealed that addition of 2 -APB ( 100 $\mu \mathrm{M})$, a potent blocker of canonical transient receptor potential (TRPc) channels (Clapham et al., 2005), to the bath abolished the $\mathrm{I}_{\mathrm{OT}}(n=5 / 5$; Fig. $2 D)$. Bath application of flufenamic acid $(100 \mu \mathrm{M})$, another putative TRPc channel antagonist (Clapham, 2007), also significantly decreased $\mathrm{I}_{\mathrm{OT}}(n=5 / 5$; Fig. $2 D)$. Then, voltage-clamp recordings were performed at a holding potential of $-60 \mathrm{mV}$ and in the presence of TTX using two types of modified aCSF. In the first experiment, $\mathrm{NaCl}$ in the aCSF was replaced by an equimolar concentration of Tris- $\mathrm{HCl}$ $\left(\mathrm{Na}^{+}\right.$-substituted aCSF), resulting in a substantially reduced inward $I_{\mathrm{OT}}(-2.8 \pm$ $0.8 \mathrm{pA}, n=5$; Fig. $2 D$ ). This current was significantly weaker than the $I_{\mathrm{OT}}$ observed during perfusion with control aCSF (control: $-13.2 \pm 3.6 \mathrm{pA} ; \mathrm{Na}^{+}$-substituted aCSF: $-2.8 \pm 0.8$ pA; Wilcoxon test, $p<$ $0.01)$. In the second experiment, the aCSF $\mathrm{Ca}^{2+}$ concentration had been reduced to $0.15 \mathrm{~mm}$. During perfusion with this low$\mathrm{Ca}^{2+}$ aCSF, OT induced an inward current of $8.8 \pm 1.5 \mathrm{pA}(n=5)$, which is not significantly different from the $I_{\mathrm{OT}}$ obtained in control aCSF (control: $-13.2 \pm$ 3.6 pA; low-Ca ${ }^{2+}$ aCSF: $8.8 \pm 1.5$ pA; Wilcoxon test, $p>0.05$; Fig. $2 D$ ). These results suggest that the $I_{\mathrm{OT}} \mathrm{LV}$ component observed at $-60 \mathrm{mV}$ holding potential involves a TRPc-like conductance carried predominantly by $\mathrm{Na}^{+}$.

In the next step, we examined the conductances involved in the HV component of $I_{\mathrm{OT}}$. Voltage-ramp protocols were performed under different pharmacological and ion substitution conditions and the $I_{\mathrm{OT}}$ at $+30 \mathrm{mV}$ holding potential was compared (Fig. 3). In the presence of 2-APB or flufenamic acid, the HV $I_{\mathrm{OT}}$ did not change significantly (control: $-182.7 \pm 54.8$ pA; 2-APB: $-200.0 \pm 54.5$ pA; flufenamic acid: $-290.5 \pm 72.2$; Mann-Whitney test, $p>0.05$; Fig. 3A). Similarly, no significant difference was observed using $\mathrm{Na}^{+}$-substituted aCSF compared with control aCSF (control: $-182.7 \pm 54.8 \mathrm{pA} ; \mathrm{Na}^{+}$-substituted aCSF: $-86.0 \pm 28.9$ pA; Mann-Whitney test, $p>0.05$; Fig. $3 B$ ). However, a decrease of the inward current observed at $+30 \mathrm{mV}$ was obtained in low- $\mathrm{Ca}^{2+}$ aCSF condition (control: $-182.7 \pm$ 54.8 pA; low-Ca ${ }^{2+}$ aCSF: $-34.3 \pm 15.9$ pA; Mann-Whitney test, $p>0.05$; Fig. $3 C$ ). This implies that the HV component involved a $\mathrm{Ca}^{2+}$-dependent conductance. A similar HV-component has earlier been described in the presence of PRL in TIDA neurons,
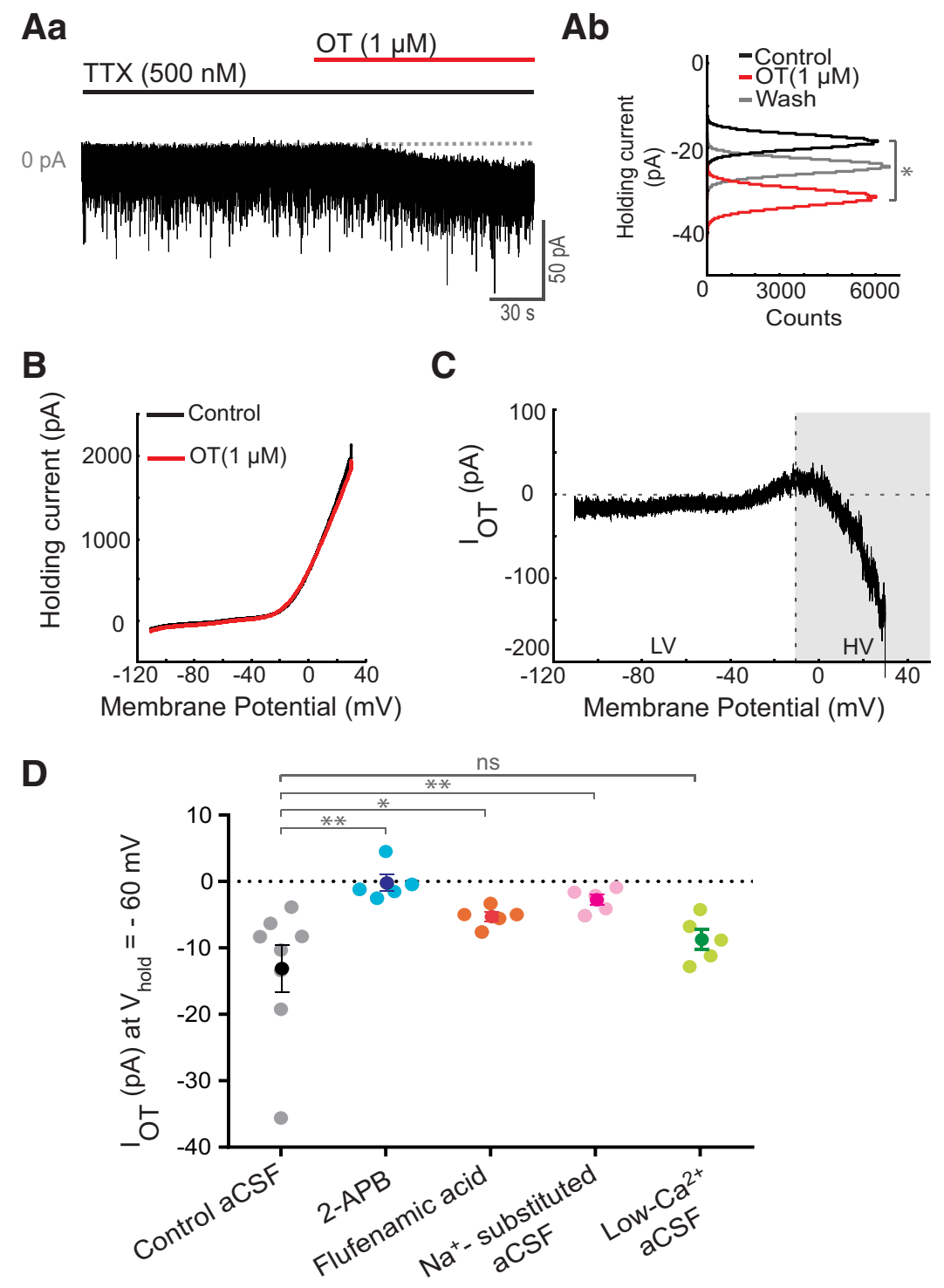

Figure 2. OT activates a net inward current. $A$, Representative voltage-clamp whole-cell recording from a TIDA neuron at a holding potential of $-60 \mathrm{mV}$ and in the presence of TTX $(\boldsymbol{A a})$, and Gaussian fits of averaged holding current frequency distribution at response (red). C, OT-induced current obtained by subtraction of the traces shown in $B(n=5$ ( $100 \mu \mathrm{M}$ ), and with the control aCSF replaced by $\mathrm{Na}^{+}$-substituted aCSF (pink) or low-Ca ${ }^{2+}$ aCSF (green). Light dots represent individual values; dark dots correspond to the mean value \pm SEM. The Wilcoxon test was used to perform the statistical analysis between each condition: ${ }^{* *} p<0.01$; n.s., Not significant.

which is also sensitive to the blocker of large conductance $\mathrm{Ca}^{2+}$ dependent $\mathrm{K}^{+}$(BK) channels, paxilline (Lyons et al., 2012). The $I_{\mathrm{OT}}$ was recorded using ramp protocol in the presence of paxilline $(2 \mu \mathrm{M})$ but no significant modulation of the HV component was detected at $+30 \mathrm{mV}$ holding potential (control: $-182.7 \pm 54.8$ pA; paxilline: $-244.9 \pm 68.6 \mathrm{pA}$; Mann-Whitney test, $p>0.05$ ). As the $\mathrm{HV}$ component overlaps with the voltage range of AP generation, spike parameters were compared in control condition and at the peak of the OT response. For each recording $(n=$ 5) $10 \mathrm{APs}$ during control and during OT response, of similar amplitude and threshold, were analyzed. No significant difference was found for either peak potential (control: $35.5 \pm 2.0 \mathrm{mV}$, OT: $35.0 \pm 2.0 \mathrm{mV}$ ), width (control: $5.2 \pm 0.4 \mathrm{~ms}$, OT: $5.2 \pm 0.3$ 
A

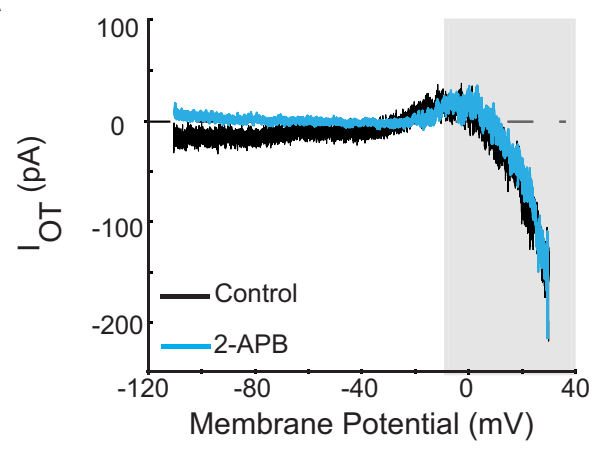

B

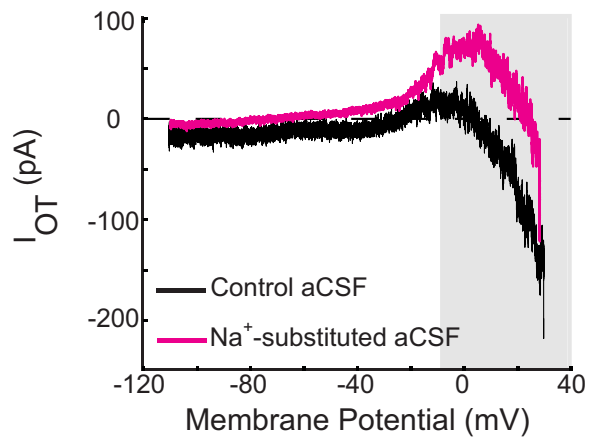

C

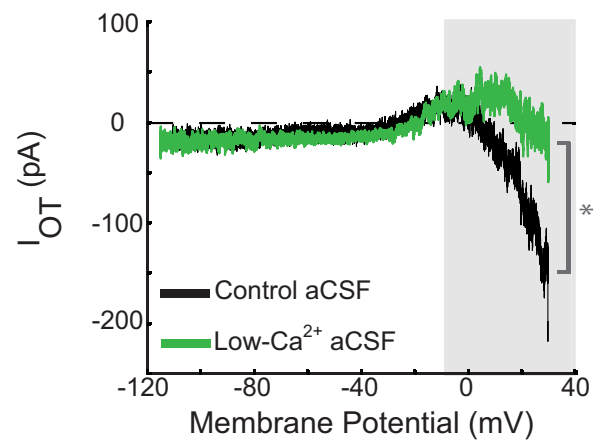

Figure 3. Low and high voltage components of the $0 T$-induced current. $A, I_{0 T}$ as recorded in voltage-clamp ramps from TIDA neurons as described in Figure $2 C$, shown in black. Blue curve shows $I_{0 T}$ obtained in the presence of $2-\mathrm{APB}$ ( $100 \mu \mathrm{m} ; n=5$ cells). Note loss of the LV component but no effect on HV component. $\boldsymbol{B}$, Red curve shows $I_{0 \text { T }}$ obtained during recording in $\mathrm{Na}^{+}$-substituted aCSF ( $n=5$ cells). Black curve, same as in $\boldsymbol{A}$. Note reduction of the LV component but no significant effect on the $\mathrm{HV}$ component by $\mathrm{Na}^{+}$substitution. $\mathrm{C}$, Green curve shows $I_{0 T}$ obtained during recording in low- $C a^{2+}$ - aCSF $(n=5$ cells). Black curve, same as in $A$. The LV component is not changed but the HV component is significantly reduced in low $\mathrm{Ca}^{2}$. The Wilcoxon test was used to perform the statistical analysis: ${ }^{*} p<0.05$; n.s., Not significant.

ms), half-width (control: $2.1 \pm 0.1 \mathrm{~ms}$, OT: $2.1 \pm 0.1 \mathrm{~ms}$ ), or area (control: $832.2 \pm 58.3$, OT: $931.1 \pm 39.8$ ).

\section{OT excites TIDA neurons in virgin female rats and lactating dams}

Having established that OT can exert powerful excitatory actions on TIDA neurons from prepubertal male rats, we were interested in determining whether similar effects can also be observed in female rats and particularly during nursing. To address these questions, we performed recordings on slices from virgin female rats and lactating dams. These preparations are less amenable to patch-clamp recordings due to age-dependent poorer visualization of cells in differential interference contrast and compromised seal stability, precluding an in-depth investigation of membrane properties. The issue of changes in excitability, however, can be monitored reliably as alterations in spiking activity or membrane potential.

In slices from virgin female rats, we observed that $49.2 \%$ ( $n=$ 29/59; Fig. $4 A a$ ) of neurons in the dmArc exhibited an excitatory response (in the form of increased firing rate and/or depolarization (see Materials and Methods; Table 1) following bath application of OT ( $1 \mu \mathrm{M}$; Fig. $4 \mathrm{Ba}, \mathrm{Ca})$. The remainder of the recorded neurons $(50.8 \%, n=30 / 59)$ did not change membrane potential or firing rate in the presence of OT; no inhibition was observed. Similar proportions were obtained in slices from lactating dams using whole-cell $(n=48)$ and loose-patch $(n=38)$ recordings. Thus, $43 \%(n=37 / 86$; Fig. $5 A a)$ of neurons exhibited an excitatory response following OT application (Table 2; Fig. 5Ba,Ca). Only one neuron $(1.2 \%, n=1 / 86)$ displayed an inhibitory response (hyperpolarization), whereas the rest of the recorded neurons $(55.8 \%, n=48 / 86)$ did not change membrane potential or firing rate in the presence of OT. It should be noted that this experimental design may underestimate the proportion of responding neurons since cells recorded in loose-patch configuration that remained silent during control and OT application $(n=$ $21 / 59$ in virgin female rats, $n=14 / 86$ in lactating dams) were classified as not responding. Responses in the form of subthreshold depolarization (or hyperpolarization) will not be detected.

According to earlier reports based on mouse recordings, regular phasic firing such as the oscillation seen in prepubertal male rats appears to be rare in TIDA cells in slices from virgin and lactating rodents (Romanò et al., 2013), and thus this electrical signature cannot be reliably used for identification of these neurons in females. To be able to identify the recorded cells as TIDA neurons, cells were therefore filled with neurobiotin during recording. Fifteen and 52 of the neurons recorded from virgin female rats and lactating dams, respectively, were successfully recovered and stained by immunofluorescence for $\mathrm{TH}$. In virgin female rats, seven cells were thus identified as TIDA neurons, i.e., displayed TH-immunoreactivity. Among these, six cells (85.7\%) responded to OT by excitation (Fig. $4 A b, B$ ), whereas only one $(14.3 \%)$ showed no response. Of the $\mathrm{TH}$-immunonegative cells (i.e., putative non-TIDA neurons), $62.5 \%(n=5 / 8$; Fig. $4 A c, C)$ responded to OT by excitation and $37.5 \%,(n=3 / 8)$ showed no response. For lactating dams, 19 cells were identified as TIDA neurons with 11 cells $(57.9 \%)$ responding to OT by excitation (Fig. $5 A b, B)$ and eight (42.1\%) showing no response. Among the putative non-TIDA neurons, $36.4 \%(n=12 / 33$; Fig. $5 A c, C)$ responded to OT by excitation, $60.6 \%,(n=20 / 33)$ showed no response and one cell (3.0\%) responded by inhibition. The proportion of responding neurons versus nonresponding neurons were not significantly different between the population as a whole, the TH-positive cells and the TH-negative cells for data from virgin female rats and lactating dams ( $\chi^{2}$ test, $\left.p>0.05\right)$.

Thus, whereas OT exerts excitatory actions on several dmArc neurons in virgin female rats and lactating dams, this response is particularly prevalent in TIDA neurons. These findings suggest that stimulation of TIDA neurons by OT can occur not only in prepubertal males, but also in females in situations of high OT release such as during nursing.

\section{Sparse innervation of TIDA neurons by OT terminals}

To investigate the possible source of endogenous OT acting on TIDA neurons, we performed double-label immunofluorescence for OT and $\mathrm{TH}$ on sections of hypothalamus (Fig. 6A,B). In brains from three male rats, the rostral, middle, and caudal levels of the Arc were studied (one section per level). TH-immuno- 
reactive (-ir) cell bodies and primary dendrites were seen clustered in the dmArc, and the external layer of the median eminence displayed a rich innervation of TH-ir terminals. OT-ir magnocellular somata were observed in characteristic distribution in the paraventricular and supraoptic nuclei, with fibers radiating in a ventrolaterally projecting arc toward the median eminence where the internal layer was heavily stained. Within the dmArc, OT-immunoreactivity was confined to fibers that were predominantly unbranched, smooth and running in a straight trajectory parallel to the third ventricle. The overall density of such fibers was low; only two to seven fibers could be seen for each section. Contacts between OT-ir fibers and TH-ir cell bodies and dendrites were only rarely observed (Fig. $6 B$ ). To evaluate whether the anatomical relationship between OT fibers and TIDA neurons is altered in different reproductive conditions, we performed the same staining protocol on rats from the three groups assessed by electrophysiology: in addition to prepubertal males, also virgin female rats $(n=4)$ and lactating dams $(n=7)$. In all animals examined, the overall density of OT-ir fibers in the dmArc was very low and contacts between such fibers and $\mathrm{TH}$-ir cell bodies were only encountered in rare instances, indistinguishable from the situation in male rats described above (Fig. 6). These findings suggest that direct synaptic interactions between OT terminals and TIDA neurons are unlikely to be the basis for the electrophysiological modulation described above in prepubertal males, virgin females or lactating dams.

\section{Discussion}

Evidence that OT modulates PRL secretion dates back over half a century (Benson and Folley, 1956), and has been evoked as a coordinating mechanism of physiological changes in the nursing mother. Yet, the possibility that such regulation may be relayed through TIDA neurons has received relatively little attention. A previous study using extracellular recordings found that OT increases the firing of neurons in this area (Yuan and Pan, 1996), but the identity of the recorded cells was not determined. Here, we show that a large proportion of neurons in the dmArc exhibit excitatory responses to OT, and that this is particularly prevalent in identified TIDA neurons. Indeed, we observed that OT excites TIDA cells both in virgin and lactating female rats, identified by TH immunoreactivity, and in prepubertal male rats, identified by electrical signature. It should be noted that the proportion of responding TIDA cells in nursing dams shown here may be an underestimation as $\mathrm{TH}$ is reported to be downregulated in the dmArc during lactation (Wang et al., 1993).

The excitatory response to OT appears to be mediated primarily through the OT-R, as it was blocked by OTA (although our data do not exclude a role for the $\mathrm{V} 1 \mathrm{a}, \mathrm{V} 1 \mathrm{~b}$ and $\mathrm{V} 2$ receptors in TIDA regulation) and that the OT-R selective agonist, TGOT, induced an excitation similar to OT. This conclusion is supported
$\mathrm{Ab}$

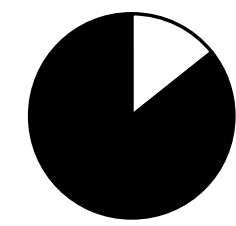

Ac

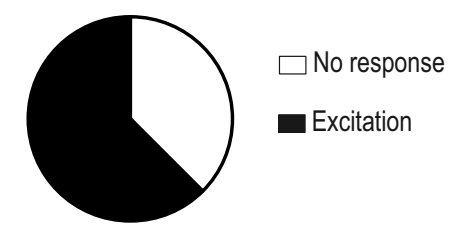

$\mathrm{Bb}$
Figure 4. OT excites arcuate nucleus neurons in virgin female rats. $A$, Pie charts illustrating the proportion of dmArc cells about OT responses for all cells $(\boldsymbol{A a} ; n=59)$, only TH-positive cells $(\boldsymbol{A} \boldsymbol{b} ; n=7)$, and only TH-negative cells $(\boldsymbol{A c} ; n=8)$ recorded in slices from virgin female rats. $\mathbf{B a}, \mathbf{C a}$, Examples of recording from neurons in the dmArc of virgin female rats that increased firing TIDA identity. Cell shown in $\mathbf{C}$ does not stain with the TH antiserum $(\boldsymbol{C b})$. Scale bars, $50 \mu \mathrm{m}$.

Table 1. Firing frequency of TIDA and non-TIDA neurons in dmArc of virgin female rats in control and during $0 \mathrm{~T}$ application

\begin{tabular}{llll}
\hline All cells & \multicolumn{2}{l}{$\begin{array}{l}\text { Only TH- } \\
\text { positive cells }\end{array}$} & $\begin{array}{l}\text { Only TH- } \\
\text { negative cells }\end{array}$ \\
\cline { 2 - 3 } & $\frac{n \text { Control }}{n \text { OT }}$ & $n$ Control OT & OT \\
\hline
\end{tabular}

Firing frequency $290.6 \pm 0.13 .0 \pm 0.2760 .8 \pm 0.34 .0 \pm 0.750 .6 \pm 0.22 .96 \pm 0.8$

$(\mathrm{Hz})$

by the expression of OT-R mRNA in the Arc (Vaccari et al., 1998). Activation of the OT-R is associated with stimulatory responses in the uterine myometrium where it couples to Gq-proteins to raise $\left[\mathrm{Ca}^{2+}\right]_{\mathrm{i}}$ (Phaneuf et al., 1993), thus promoting contractility. OT-R-mediated excitation has also been described in the CNS in, e.g., the amygdala (Huber et al., 2005), where the peptide has been implicated in emotional responses (Stoop, 2012).

We found that OT directly depolarizes TIDA cells. (The present findings do not, however, exclude that OT can also modulate synaptic input to TIDA neurons). This excitation is mediated by net increases in inward current, which exhibits similarities with current induced by OT in vagal neurons. Indeed, both currents are TTX-insensitive, mainly carried by $\mathrm{Na}^{+}$, voltage-dependent and modulated by $\mathrm{Ca}^{2+}$ (Raggenbass and Dreifuss, 1992). Further characterization of the inward current in TIDA neurons identified two distinct components. The LV component is sensitive to 2-APB and flufenamic acid applications and $\mathrm{Na}^{+}$substitution, indicative of a mixed cation conductance of the TRPc type (Strübing et al., 2001). A current with the same characteristics is 
Aa

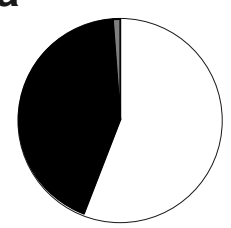

Ab

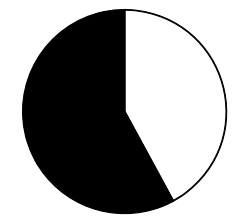

Ac

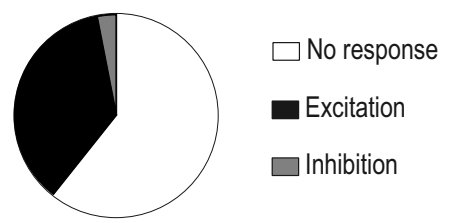

$\mathrm{Bb}$

$\mathrm{Ba}$

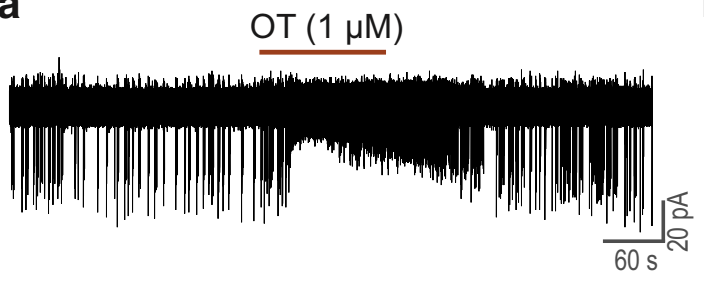

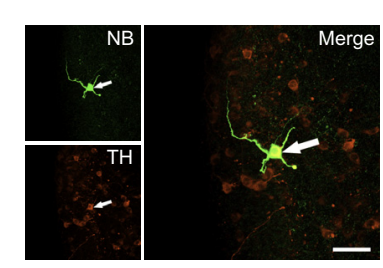

Cb

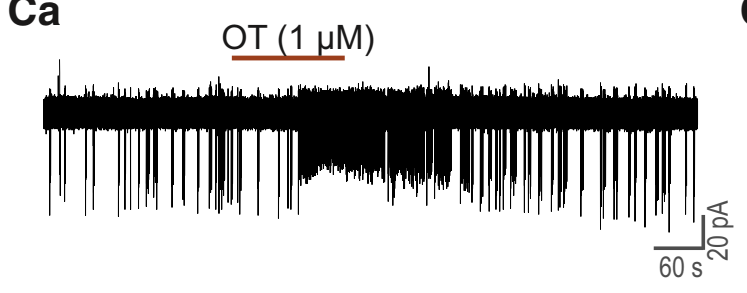

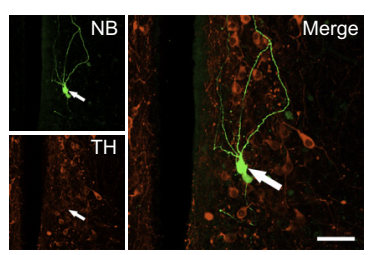

Figure 5. OT excites arcuate nucleus neurons in lactating female dams. $\boldsymbol{A}$, Pie charts illustrating the proportion of dmArc cells about 0 T responses for all cells $(\boldsymbol{A a} ; n=86)$, only TH-positive cells $(\boldsymbol{A} \boldsymbol{b} ; n=19)$ and only TH-negative cells $(\boldsymbol{A c} ; n=33)$ recorded in slices from lactating dams. $\mathbf{B a}, \mathbf{C a}$, Examples of recordings from neurons in the dmArc of lactating female rats that exhibit increased firing following application of OT (1 $\mu \mathrm{M})$ in TIDA (Ba) and non-TIDA (Ca) neurons. The recorded cells were filled with neurobiotin (NB; green) and stained by immunofluorescence for TH (red), shown in confocal micrographs in $\boldsymbol{B} \boldsymbol{b}, \boldsymbol{C} \boldsymbol{b}$. Green and red channels shown separately in smaller panels; larger panels shows merged image. The cell in $\mathbf{B a}$ exhibits TH-immunoreactivity $(\boldsymbol{B} \boldsymbol{b})$, indicating its TIDA identity. Cell shown in $\mathbf{C}$ does not stain with the TH antiserum $(\boldsymbol{C} \boldsymbol{b})$. Scale bars, $50 \mu \mathrm{m}$.

subject to modulation by thyrotropin-releasing hormone and PRL in TIDA cells (Lyons et al., 2010; Lyons et al., 2012), agents that, like OT, shift these neurons from phasic to tonic firing. Thus, our findings further implicate a TRPc-like current as an electrophysiological "switch" between discharge configurations in TIDA neurons. In neuroendocrine neurons expressing gonadotropin-releasing hormone, the peptide kisspeptin has been shown to augment TRPc-like conductances by activating Gq signaling mediated via phospholipase C (Zhang et al., 2008); the final stimulation of TRPc channels may involve increased intracellular $\mathrm{Ca}^{2+}$ and/or diacylglycerol signaling. It remains to be determined whether similar intracellular signaling mediates the OT-induced activation of the mixed cationic inward current in TIDA neurons. The second component (HV) appears to be carried by $\mathrm{Ca}^{2+}$ or a $\mathrm{Ca}^{2+}$-sensitive conductance. PRL activates a $\mathrm{Ca}^{2+}$-dependent inward current of similar voltage range and amplitude in TIDA neurons (Lyons et al., 2012). Yet, the PRL- and OT-induced HV components differ in important regards. Although PRL administration is accompanied by a broadening of action potentials (Lyons et al., 2012), we failed to observe such changes in the presence of OT. Furthermore, the PRL HV component is sensitive to $\mathrm{BK}$ channel blockade by paxilline, whereas the OT HV component is not. The coincidence of spike broadening (a high-voltage range event) and BK-dependence of the HV component during PRL application, and the absence of both factors with OT application, may be an indirect indication that modulation of BK channels is an important, if not necessary, element in determining spike duration in TIDA neurons. The exact nature of the OT-induced changes at a depolarized range remains, however, to be determined. This includes identifying if the HV changes induced by OT are also mediated by the OT-R as was done for the depolarization at resting membrane potential (present results).

Cumulatively, the actions of OT on TIDA neurons provide a powerful excitatory influence. This may at first seem surprising as OT is often discussed as a PRL secretagogue (Bertram et al., 2010), whereas increased TIDA activity is predicted to decrease PRL release. However, there is evidence that the actions of OT on PRL release are site-specific. Whereas systemic administration of OT results in increased plasma PRL concentration (Lumpkin et al., 1983; Samson et al., 1986; Arey and Freeman, 1989; Egli et al., 2006), infusion of the peptide into the third ventricle actually causes a marked suppression of circulating PRL levels (Lumpkin et al., 1983; Mogg and Samson, 1990; Yuan and Pan, 1996). Although treatment with a dopamine D2 receptor antagonist does not fully block the reduction of plasma PRL following central administration of OT (Mogg and Samson, 1990), infusion of OT into the third ventricle does cause increased dopamine output toward the pituitary in ovariectomized estrogen-treated female rats (Yuan and Pan, 1996). Thus, we propose that promotion of tonic firing, resulting in strengthened dopaminergic inhibition at the lactotroph membrane, may contribute to central OT-mediated suppression of PRL release.

Together with previous observations, the present findings suggest a role for OT actions on TIDA neurons in hormonal homeostasis. In lactation, a suckling-induced surge of plasma OT derived from a switch to bursting in magnocellular neurons (Lincoln and Wakerley, 1974) will stimulate lactotrophs to release PRL (Lumpkin et al., 1983). Circulating OT penetrates the blood-brain barrier poorly (Ermisch et al., 1985; McEwen, 2004) and so is unlikely to act directly on TIDA neurons as the dmArc is likely to lie within this barrier (Smith and Ferguson, 2014). We also failed to observe any significant degree of direct contacts between OT axons and TIDA cell bodies in any of the conditions studied (prepubertal males, virgin females, and lactating dams; present results). However, stimuli that raise hormonal posterior pituitary OT output also cause, with a delay (Ludwig, 1995), an increase in the dendritic release of OT from magnocellular neurons (Bergquist and Ludwig, 2008). Dendritic release is believed to be the cause of the exceptionally high ambient levels of this peptide in brain parenchyma (Dogterom et al., 1977) and central OT seems to be able to spread over distant area (Leng and Ludwig, 2008). Furthermore, magnocellular dendrites make contact with the ependymal cell layer lining the ventricular system (Ludwig and Leng, 2006) and excitation of OT-containing magnocellular cell bodies is followed by increased OT levels in the CSF, but not necessarily in plasma (Jones et al., 1983; Coombes et al., 1991; Engelmann et al., 2000; Gimpl and Fahrenholz, 2001). Thus, dendritic OT release can make a major contribution to CSF concentration (Leng and Ludwig, 2008). Therefore, either through 
Table 2. Firing frequency and membrane potential change of TIDA and non-TIDA neurons in dmArc of lactating dams in control and during 0T application

\begin{tabular}{|c|c|c|c|c|c|c|c|c|c|}
\hline & \multicolumn{3}{|c|}{ All cells } & \multicolumn{3}{|c|}{ Only TH-positive cells } & \multicolumn{3}{|c|}{ Only TH-negative cells } \\
\hline & $n$ & Control & OT & $n$ & Control & OT & $n$ & Control & OT \\
\hline Firing frequency $(\mathrm{Hz})$ & 33 & $0.4 \pm 0.1$ & $2.4 \pm 0.3$ & 8 & $0.4 \pm 0.2$ & $3.4 \pm 0.8$ & 11 & $0.33 \pm 0.1$ & $2.25 \pm 0.4$ \\
\hline Membrane potential (mV) & 4 & $-51.1 \pm 0.7$ & $-45.2 \pm 1.1$ & 3 & $-52.4 \pm 0.7$ & $-46.3 \pm 6.2$ & 1 & -46.9 & -41.9 \\
\hline
\end{tabular}

parenchymal diffusion or, perhaps more likely, relayed via the CSF, OT could access and excite the TIDA cells (located adjacent to the ventricular wall). Such a delayed activation of TIDA neurons following an OT surge could provide a safety mechanism to ensure that increases in plasma PRL are temporally constrained. This arrangement could as well apply to other physiological situations where OT and PRL act in parallel (e.g., during proestrous or mating). Indeed, we show here that excitation of TIDA neurons by OT is seen under several different reproductive conditions, including prepubertal males, virgin females, and lactating dams. (Although further studies are needed to determine whether there are fluctuations in responsiveness during the different stages of the estrous cycle, it can be noted that the proportions of OT-responsive TIDA neurons was not different from that in the lactating group. The availability of circulating OT, however, does increase significantly during lactation; whether OT, under these conditions may pass into the dmArc from the blood remains to be addressed.)

An alternative scenario for OT-TIDA interactions during lactation also merits consideration. During lactation, $\mathrm{TH}$ expression and dopamine output from TIDA neurons decreases (Wang et al., 1993). Concurrently, expression of the PRL-releasing peptide enkephalin (Lien et al., 1976) is induced in these neurons (Merchenthaler, 1993). It has recently been proposed that this transcriptional switch may turn TIDA cells from an inhibitory to a stimulating influence on pituitary PRL release (Romano et al., 2011). In this scenario, central oxytocinergic excitation of TIDA cells may form part of a positive feedforward mechanism to ensure sustained PRL release so that the demands on milk ejection posed by circulating OT are complemented by milk production.

In conclusion, we present evidence and an electrophysiological basis for powerful actions of OT on TIDA neuron excitability that can be activated in nursing conditions when circulating PRL is high, as well as in states of low PRL demand (prepubertal male rats). These data suggest a novel mechanism for coordination in the hormonal control of lactation.
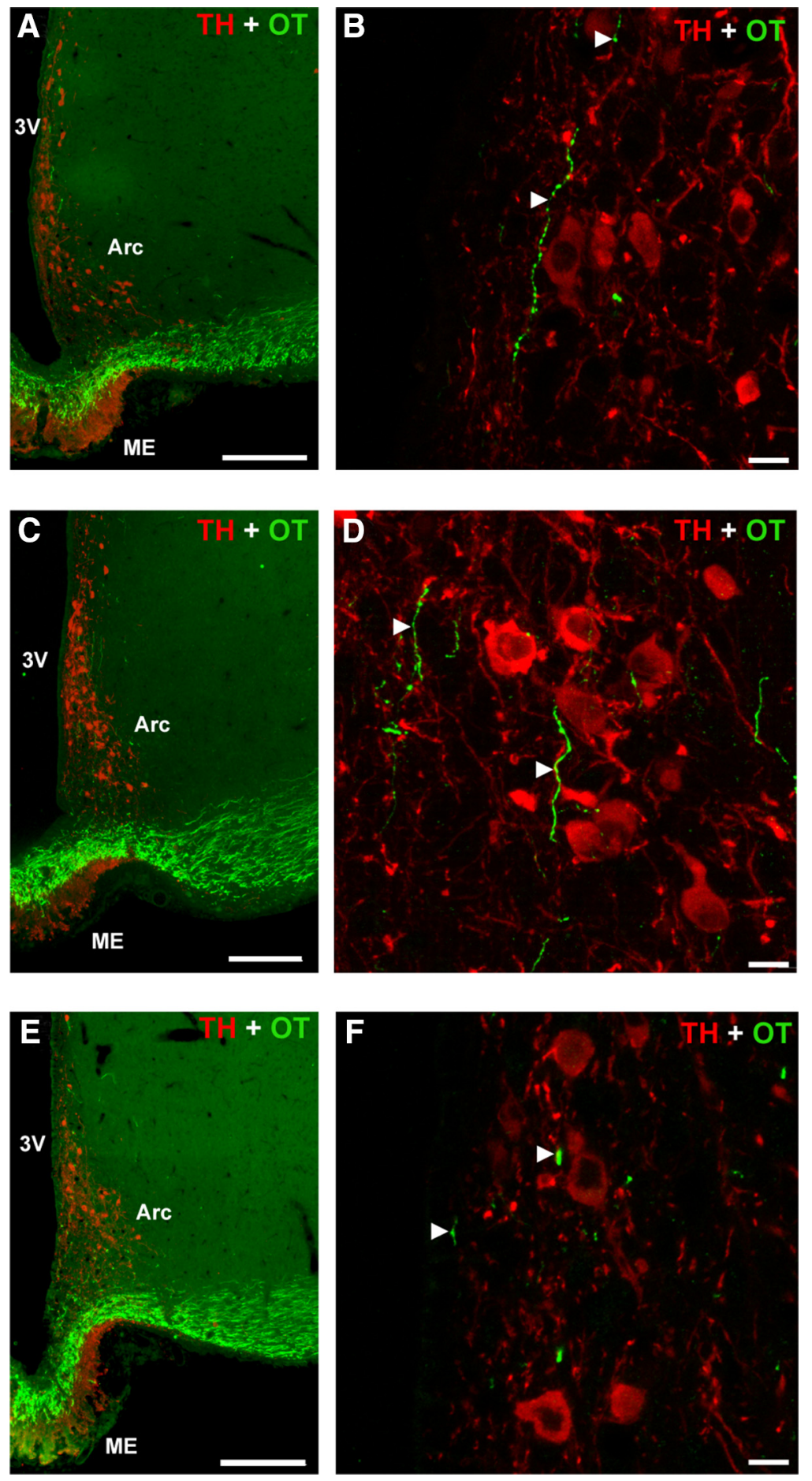

Figure 6. OT innervation of TIDA neurons is sparse. $\boldsymbol{A}, \boldsymbol{C}, \boldsymbol{E}$, Fluorescence micrographs from coronal sections of the male $(\boldsymbol{A})$, virgin female $(\boldsymbol{C})$, and lactating $(\boldsymbol{E})$ rat hypothalamus labeled with immunofluorescence for TH (red) to identify TIDA neurons and OT (green). Note dense 0T-immunoreactive terminals of the median eminence (ME) but only occasional 0T-immunoreactive axons in the Arc. Scale bars, $200 \mu \mathrm{m} . \boldsymbol{B}, \boldsymbol{D}, \boldsymbol{F}$, Confocal micrographs of male $(\boldsymbol{B})$, virgin female $(\boldsymbol{D})$, and lactating $(\boldsymbol{F})$ rat hypothalamus sections stained for TH and OT immunofluorescence as in $\boldsymbol{A}$. Only scattered OT-immunoreactive fibers (arrowheads) are seen and very few contact points with TIDA neurons can be observed. 3V, Third ventricle; scale bars, $10 \mu \mathrm{m}$. 


\section{References}

Arey BJ, Freeman ME (1989) Hypothalamic factors involved in the endogenous stimulatory rhythm regulating prolactin secretion. Endocrinology 124:878-883. CrossRef Medline

Benson GK, Folley SJ (1956) Oxytocin as stimulator for the release of prolactin from the anterior pituitary. Nature 177:700. CrossRef Medline

Bergquist F, Ludwig M (2008) Dendritic transmitter release: a comparison of two model systems. J Neuroendocrinol 20:677-686. CrossRef Medline

Bertram R, Helena CV, Gonzalez-Iglesias AE, Tabak J, Freeman ME (2010) A tale of two rhythms: the emerging roles of oxytocin in rhythmic prolactin release. J Neuroendocrinol 22:778-784. CrossRef Medline

Björklund A, Falck B, Stenevi U (1971) Classification of monoamine neurones in the rat mesencephalon: distribution of a new monoamine neurone system. Brain Res 32:269-285. CrossRef Medline

Bronson FH (1991) Mammalian reproductive biology. Chicago: University of Chicago.

Clapham DE (2007) SnapShot: mammalian TRP channels. Cell 129:220. CrossRef Medline

Clapham DE, Julius D, Montell C, Schultz G (2005) International union of pharmacology. XLIX. Nomenclature and structure-function relationships of transient receptor potential channels. Pharmacol Rev 57:427450. CrossRef Medline

Coombes JE, Robinson IC, Antoni FA, Russell JA (1991) Release of oxytocin into blood and into cerebrospinal fluid induced by naloxone in anaesthetized morphine-dependent rats: the role of the paraventricular nucleus. J Neuroendocrinol 3:551-561. CrossRef Medline

Dogterom J, Van Wimersma Greidanus TB, Swabb DF (1977) Evidence for the release of vasopressin and oxytocin into cerebrospinal fluid: measurements in plasma and CSF of intact and hypophysectomized rats. Neuroendocrinology 24:108-118. CrossRef Medline

Du Vigneaud V, Ressler C, Trippett S (1953) The sequence of amino acids in oxytocin, with a proposal for the structure of oxytocin. J Biol Chem 205: 949-957. Medline

Egli M, Bertram R, Toporikova N, Sellix MT, Blanco W, Freeman ME (2006) Prolactin secretory rhythm of mated rats induced by a single injection of oxytocin. Am J Physiol Endocrinol Metab 290:E566-E572. CrossRef Medline

Engelmann M, Wotjak CT, Ebner K, Landgraf R (2000) Behavioural impact of intraseptally released vasopressin and oxytocin in rats. Exp Physiol 85:125S-130S. CrossRef Medline

Ermisch A, Barth T, Rühle HJ, Skopková J, Hrbas P, Landgraf R (1985) On the blood-brain barrier to peptides: accumulation of labelled vasopressin, DesGlyNH2-vasopressin and oxytocin by brain regions. Endocrinol Exp 19:29-37. Medline

Freeman ME, Kanyicska B, Lerant A, Nagy G (2000) Prolactin: structure, function, and regulation of secretion. Physiol Rev 80:1523-1631. Medline

Fuxe K (1963) Cellular localization of monoamines in the median eminence and in the infundibular stem of some mammals. Acta Physiol Scand 58: 383-384. CrossRef Medline

Garcia S, Fourcaud-Trocmé N (2009) OpenElectrophy: an electrophysiological data- and analysis-sharing framework. Front Neuroinform 3:14. CrossRef Medline

Gimpl G, Fahrenholz F (2001) The oxytocin receptor system: structure, function, and regulation. Physiol Rev 81:629-683. Medline

Huber D, Veinante P, Stoop R (2005) Vasopressin and oxytocin excite distinct neuronal populations in the central amygdala. Science 308:245-248. CrossRef Medline

Jones PM, Robinson IC, Harris MC (1983) Release of oxytocin into blood and cerebrospinal fluid by electrical stimulation of the hypothalamus or neural lobe in the rat. Neuroendocrinology 37:454-458. CrossRef Medline

Leng G, Ludwig M (2008) Neurotransmitters and peptides: whispered secrets and public announcements. J Physiol 586:5625-5632. CrossRef Medline

Lien EL, Fenichel RL, Garsky V, Sarantakis D, Grant NH (1976) Enkephalinstimulated prolactin release. Life Sci 19:837-840. CrossRef Medline

Lincoln DW, Wakerley JB (1974) Electrophysiological evidence for the activation of supraoptic neurones during the release of oxytocin. J Physiol 242:533-554. CrossRef Medline

Ludwig M (1995) Functional role of intrahypothalamic release of oxytocin and vasopressin: consequences and controversies. Am J Physiol 268: E537-E545. Medline

Ludwig M, Leng G (2006) Dendritic peptide release and peptide-dependent behaviours. Nat Rev Neurosci 7:126-136. CrossRef Medline
Lumpkin MD, Samson WK, McCann SM (1983) Hypothalamic and pituitary sites of action of oxytocin to alter prolactin secretion in the rat. Endocrinology 112:1711-1717. CrossRef Medline

Lyons DJ, Broberger C (2014) TIDAL WAVES: network mechanisms in the neuroendocrine control of prolactin release. Front Neuroendocrinol 35: 420-438. CrossRef Medline

Lyons DJ, Horjales-Araujo E, Broberger C (2010) Synchronized network oscillations in rat tuberoinfundibular dopamine neurons: switch to tonic discharge by thyrotropin-releasing hormone. Neuron 65:217-229. CrossRef Medline

Lyons DJ, Hellysaz A, Broberger C (2012) Prolactin regulates tuberoinfundibular dopamine neuron discharge pattern: novel feedback control mechanisms in the lactotrophic axis. J Neurosci 32:8074-8083. CrossRef Medline

Manning M, Stoev S, Chini B, Durroux T, Mouillac B, Guillon G (2008) Peptide and non-peptide agonists and antagonists for the vasopressin and oxytocin V1a, V1b, V2 and OT receptors: research tools and potential therapeutic agents. Prog Brain Res 170:473-512. CrossRef Medline

McEwen BB (2004) Brain-fluid barriers: relevance for theoretical controversies regarding vasopressin and oxytocin memory research. Adv Pharmacol 50:531-592, 655-708. CrossRef Medline

Merchenthaler I (1993) Induction of enkephalin in tuberoinfundibular dopaminergic neurons during lactation. Endocrinology 133:2645-2651. CrossRef Medline

Mogg RJ, Samson WK (1990) Interactions of dopaminergic and peptidergic factors in the control of prolactin release. Endocrinology 126:728-735. CrossRef Medline

Ott I, Scott JC (1910) The galactogogue action of the thymus and corpus luteum. Proc Soc Exp Biol Med 8:49. CrossRef

Parker SL, Armstrong WE, Sladek CD, Grosvenor CE, Crowley WR (1991) Prolactin stimulates the release of oxytocin in lactating rats: evidence for a physiological role via an action at the neural lobe. Neuroendocrinology 53:503-510. CrossRef Medline

Phaneuf S, Europe-Finner GN, Varney M, MacKenzie IZ, Watson SP, López Bernal A (1993) Oxytocin-stimulated phosphoinositide hydrolysis in human myometrial cells: involvement of pertussis toxin-sensitive and -insensitive G-proteins. J Endocrinol 136:497-509. CrossRef Medline

Raggenbass M, Dreifuss JJ (1992) Mechanism of action of oxytocin in rat vagal neurones: induction of a sustained sodium-dependent current. J Physiol 457:131-142. CrossRef Medline

Romano N, Yip S, Hodson D, Guillou A, Parnaudeau S, Tronche F, Bonnefont X, Bunn SJ, Grattan DR, Mollard AO, Martin AO (2011) Phenotipic and functional plasticity in hypothalamic dopamine neurons associated with robust electrophysiological properties. Soc Neurosci Abstr 389.02.

Romanò N, Yip SH, Hodson DJ, Guillou A, Parnaudeau S, Kirk S, Tronche F, Bonnefont X, Le Tissier P, Bunn SJ, Grattan DR, Mollard P, Martin AO (2013) Plasticity of hypothalamic dopamine neurons during lactation results in dissociation of electrical activity and release. J Neurosci 33: 4424-4433. CrossRef Medline

Samson WK, Lumpkin MD, McCann SM (1986) Evidence for a physiological role for oxytocin in the control of prolactin secretion. Endocrinology 119:554-560. CrossRef Medline

Smith PM, Ferguson AV (2014) Metabolic signaling to the central nervous system: routes across the blood brain barrier. Curr Pharm Des 20:13921399. CrossRef Medline

Stoop R (2012) Neuromodulation by oxytocin and vasopressin. Neuron 76: 142-159. CrossRef Medline

Strübing C, Krapivinsky G, Krapivinsky L, Clapham DE (2001) TRPC1 and TRPC5 form a novel cation channel in mammalian brain. Neuron 29: 645-655. CrossRef Medline

Vaccari C, Lolait SJ, Ostrowski NL (1998) Comparative distribution of vasopressin $\mathrm{V} 1 \mathrm{~b}$ and oxytocin receptor messenger ribonucleic acids in brain. Endocrinology 139:5015-5033. CrossRef Medline

Wang HJ, Hoffman GE, Smith MS (1993) Suppressed tyrosine hydroxylase gene expression in the tuberoinfundibular dopaminergic system during lactation. Endocrinology 133:1657-1663. CrossRef Medline

Yuan ZF, Pan JT (1996) Stimulatory effect of central oxytocin on tuberoinfundibular dopaminergic neuron activity and inhibition on prolactin secretion: neurochemical and electrophysiological studies. Endocrinology 137:4120-4125. CrossRef Medline

Zhang C, Roepke TA, Kelly MJ, Rønnekleiv OK (2008) Kisspeptin depolarizes gonadotropin-releasing hormone neurons through activation of TRPC-like cationic channels. J Neurosci 28:4423-4434. CrossRef Medline 